\title{
The nexus between post conflict societies and their capacity to respond to the ebola epidemic in Mano River Union
}

\author{
Hikimatu Tuntei-Ya Mohammed ${ }^{\mathrm{a}, 1, *}$, Benjamin Agordzo $^{\mathrm{b}, 2}$ \\ a,b Kofi Annan International Peacekeeping Training Centre, Ghana \\ ${ }^{1}$ Email: hikiteiya@gmail.com* \\ * corresponding author
}

\section{ARTICLE INFO}

Article history

Received, 22-nd May 2021

Revised, 21 $1^{\text {st }}$ August 2021

Accepted, $22^{\text {-nd }}$ July 2021

\section{Keywords}

Conflict society

Epidemic

Ebola

Africa
ABSTRACT (10PT)

The Ebola crisis in the Mano River States and inadequate state responses to the outbreak heightened the challenges post conflict societies face during emergencies. There have been enough literature discussing the issues of Ebola especially in the Mano River Union; however, there is little discussion on the capacity of the Mano River Union to respond to the Ebola epidemic. Against this background, the study sought to investigate the nexus between post conflict societies and their capacity to respond to the Ebola epidemic in the Mano River Union. A non-empirical qualitative case study approach involving extensive review of secondary data in the form of books, journals, internet sites and conference papers was adopted. The results showed that all the countries in the sub-region were unprepared for the outbreak. Even though some countries had disaster management divisions, none had any disaster management plans in place hence the Ebola Virus Disease and its subsequent crisis could not have been anticipated. Following the findings, a strong case has been made for countries in the sub-region to have disaster management plans and other early warning and resilient systems in place in place to reduce the scale of the outbreak and the high number of deaths.

This is an open access article under the CC-BY-SA license.

\section{Introduction}

Africa's history as a continent is replete with conflict (Camacho et al., 2014). One may even assert that the major current that runs through Africa: from North to South, East to West and Central is conflict and wars. Since the 1960's, series of civil wars had taken place in Africa (Baize et al., 2014; Forrester et al., 2014; Wamala, Lukwago, Malimbo, Nguku, et al., 2012).

In the recent past, Africa countries have had several conflicts and currently the problem is far from being abated. This according to - has caused many untold suffering on its people and has also taken a huge toll on the development of the continent as a whole (Tracking, 2016; UNISDR, 2016). In 2006, Africa recorded 17 conflicts in all; the consequences of these conflicts vary a lot in scope, intensity, and nature. Of all the countries in the Greater Horn of Africa only two (Djibouti and Tanzania) could be said to be relatively stable, although they also had a fair share of their internal skirmishes. Conflict has taken an immeasurable toll on human lives, leaving people dead, maimed, and either internally displaced or as refugees in other nations(Alexander et al., 2015a; Union, 2015). Conflicts put a lot of pressure on Government institutions and in most cases disrupt service delivery. For instance, health and educational services are severely disrupted. During conflicts, faculty of higher institutions, health care workers, medical school and hospital administrators, often leave the country. In addition, buildings including health centres are badly damaged by armed forces or shell fire (Frieden et al., 2014). 
The three countries of the Mano River Basin have close ethnic and historical ties. West African States comprising of Guinea, Liberia and Sierra Leone form the Mano River Union that was established in 1973 as a customs and economic union between these states to promote regional economic integration(Lisgis et al., 2014; SSL \& International, 2014). The Mano River Agreement signed in 1973 gives evidence that the three States can co-operate to strengthen and consolidate this common market and also take measures to prevent conflict in the region. These efforts however, have been frustrated by political instability and violent armed conflicts that have oppressed the region in the past decade, firstly in Liberia then Sierra Leone. These three countries are currently facing a tough challenge in resolving these persistent political and security tensions within the sub-region(Bryman, 2012; Mano River Union Advocacy, 2015). This is affecting them in developing stable democracies and effective state institutions. The root causes of these prolonged conflicts in the Mano River Union can be attributed to interrelated internal and external factors. They include bad governance, under development, gender inequalities, widespread poverty, and exploitation of natural resources or colonial legacy(Albrecht \& Jackson, 2014).

These conflicts have directly and indirectly impacted the lives and livelihoods of hundreds of thousands of civilians in the MRU especially women and children. There is a deliberate attempt of targeting civilians and this has generated unprecedented levels of population displacement, leading to Guinea serving as a haven for refugees fleeing the conflicts in Liberia and Sierra Leone(Alexander et al., 2015b). For several years, Guinea has been the host of the highest number of refugees in Africa. The socioeconomic situation of all three countries has deteriorated drastically and extreme poverty is widespread. The conflicts have also taken a regional dimension as a result of ineffective disarmament of ex-combatants combined with limited opportunities to transform the ex-combatants into productive citizens in the various counties(Arieff \& McGovern, 2013).

It was in the midst of this situation that a 'mysterious' disease started spreading silently in a village in Guinea on 26 December 2013(Frieden et al., 2014; Gire et al., 2014). It was initially not identified as Ebola until 21 March 2014. The outbreak of Ebola Virus Disease (EVD) in some parts of West Africa can be said to be the largest, longest, most severe and very complex in the nearly four-decade history of this disease in the world. The human, social and economic impact of the EVD outbreak has been colossal(Theo, 2015). The death toll in the three Mano River Union countries stood at 11,000 out of 27,000 confirmed cases of Ebola. This epidemic has led to more than 20,000 children either losing one or both parents and at least 3,000 women have been widowed. The economies of these countries have gone into free-fall, resulting in a projected real GDP growth rates in 2014 declining from 4.5 percent to 1.1 percent in Guinea, 11.3 percent to 7.1 percent in Sierra Leone and 5.9 percent to 0.7 percent in Liberia(Tiaji, 2014).

Mano River Union countries are post conflict societies, which due to prolonged conflicts, have experienced drop in Gross Domestic Products (GDPs), political instability and weak organizational/institutional structures making these countries inadequately prepared for any form of epidemic. Unfortunately, the Mano River Union was the hardest hit by the outbreak of the Ebola Virus Disease in West Africa(UNDP, 2015). Because of the political instability and the breakdown of state institutions, especially the health institution it was obvious that these countries were ill prepared to deal with an epidemic of such magnitude(United Nations development group, 2015). Indeed, as part of the security sector reform processes in post conflict societies, emergency preparedness plans are normally not put in place and this results into high death tolls when societies are hit by epidemics(Secretary, 2016; Team, 2014). The extant literature on the issue of Ebola discusses issues such as factors that might have led to the emergence of Ebola in the sub-region, the Ebola recover, new challenges, new global response and Responsibility. However, there is little discussion on the capacity of the Mano River Union to respond to the Ebola epidemic(Chan, 2014; Kodjo, 2015). Hence, this study seeks to investigate the nexus between post conflict societies and their capacity to respond to the Ebola epidemic in the Mano River Union.

\section{Method}

The present study employs the qualitative research approach. Qualitative research method is defined as a research strategy that usually emphasises words rather than quantification in the collection and analysis of data. As a research strategy, it is broadly inductivist, constructionist, and interpretivist. However, not all researchers subscribe to all these three features. Qualitative research unlike 
quantitative research strategy often seek deeper understanding of a situation, unlike quantitative research that is more concerned with numbers and measuring phenomena. On the other hand, qualitative research methodology often provides meaning, context and depth.

For the purpose of this study, this qualitative strategy will be used to assess the capacity of post conflict societies to respond to the Ebola epidemic through the use of secondary data. The case study approach is also employed in this study(Alexis, 2014). Case studies are a design of inquiry found in many fields, especially evaluation, in which the researcher develops an in-depth analysis of a case often a program, event, activity, process, or one or more individuals. Cases are bounded by time and activity, and researchers collect detailed information using a variety of data collection procedures over a sustained period of time. In other words, a case study can be defined as an intensive, holistic description and analysis of a single instance, phenomenon, or social unit. This is an indication that the use of a case study is when the case becomes the unit around which there are boundaries(BBC, 2014a). In this research, while the Ebola epidemic might have hit other countries, this study concentrates on countries in the Mano River Union as a case study. The case study would however not make use of primary data rather books, journals, internet sites and conference papers will be the main source of data for the research in understanding the nexus between these post conflict societies and their capacity to respond to the Ebola epidemic in the Mano River Union.

The research will focused on the preparedness of the Mano River Union Countries to respond to the Ebola Virus Disease. Considering the fact that the Mano River Union countries are post conflict societies, the study will adopt the Disaster Risk Management Cycle. The three countries in the Mano River Basin have shared close historical and ethnic ties. The Mano River Union, comprising of the West African States Guinea, Liberia and Sierra Leone, was established in 1973 as a customs and economic union to foster relationships between the member states in other to promote regional economic integration. The Mano River Agreement of 1973 gives evidence that the three States can co-operate to revitalize and consolidate a common market and take measures to prevent conflict in the region.

The units of analysis for this research are social artificial, which includes concrete objects such as books, poems, paintings and automobiles. In the present study, the data for the study includes published reports/documents from the Mano River Union, documents from the websites of WHO, UNICEF, UNHCR, and other United Nations organizations. In addition, journal publications and books on conflict and Ebola virus disease in West Africa will also be utilised. The following keywords were used; conflict in Africa, post-conflict, Mano River Union, Ebola Virus Disease, epidemics, Liberia, Sierra Leone, Guinea, developing countries. All English language articles relating to postconflict societies and their responds to the Ebola epidemic in Mano River Union were considered given preference to peer reviewed journals. Only full text documents and publications in the last 20 years were selected in order to get literature for all the countries in the Mano River Union. The conceptual framework and theories were used to analyse the preparedness of the Mano River Union. Numerous studies explaining the various reforms that took place in the Mano River Union were identified from internet databases and books.

\section{Results and Discussion}

There were themes emerged from this study which is described in this following sections:

\subsection{Security Sector Reforms in Mano River Union}

The template is designed so that author affiliations are not repeated each time for multiple authors of the same affiliation. Please keep your affiliations as succinct as possible (for example, do not differentiate among departments of the same organization). This template was designed for two affiliations.

The Ebola outbreak provided the first significant test case for the efforts to rebuild the Mano River Union after the several years of conflicts. In spite of Sierra Leone's post-war progress towards its ultimate goal of a middle-income country, public services before the outbreak of the Ebola virus disease were underdeveloped. As at 2010, Sierra Leone had 0.02 doctors per 1,000 people and the situation was exacerbated by the obliteration of healthcare workers during the crisis. The Sierra Leone government's unwillingness to recognize the outbreak as a potential security threat contributed to its 
late containment and thus the massive spread throughout the country(Mano River Union Advocacy, 2015; River, 2015).

This was very evident in their delay in invocation of the national security architecture. This was one of the few centralized networks through which the Sierra Leone government could co-ordinate an immediate nationwide response and also use of pre-designed structures so crucial to responding to such outbreaks. In addition, the decision to empower the Ministry of Health rather than including the Office of National Security (ONS) in coordinating the response had important implications for the epidemic's subsequent handling(Bogoch et al., 2015). In some countries security forces were regularly used in times of national crisis due to their unique ability and training to meet the demands posed by extraordinary events such as the Ebola crisis but Sierra Leone lacked the processes to co-ordinate such a response. The disaster management directorate under the office of the national security was in the process of developing their emergency preparedness plan when the Ebola epidemic occurred. Security experts argue that, If such measures been in place and tested earlier, the ONS might have forged a stronger role for itself and potentially guiding the executive towards a security-based response from the very start.

As the Liberian Civil War came to an end in 2003, the United States partnered with the United Nations and the Government of Liberia to rebuild the Liberian security sector. The Ebola crisis has shown the importance of this work and has illustrated that investments in security sectors reforms will establish more than just stable borders and avoid more than just civil war but they will also build state capacity to respond to any form of crisis(Katz \& Tobian, 2014). The deployment of the Operation Onward Liberty in 2010 was efforts towards rebuilding the armed forces of Liberia (AFL). Its origins lie in the 2003 Comprehensive Peace Agreement that was signed in Accra and ended the thirteen years Liberian civil war. The peace agreement tasked the United States to take the lead in reforming the AFL and the United Nations also tasked to reform Liberian National Police (LNP).

The Ebola virus subsumed all health care activities in the West African region and became the biggest crisis to have occurred in the sub-region. This was a significant threat to Liberian stability since the civil war. The AFL, although an imperfect institution, had proven to be the most reliable pillar in an otherwise hollow Liberian state. As the Liberian president scrambles to control the flight of public officials from Liberia, the AFL had so far stood fast, enforcing quarantines, upgrading airstrips, building emergency treatment units, and screening travel at the country's porous borders.

Even though the AFL stood up to help control the Ebola epidemic, they also had their own share of failures. In late August, 2014, as the virus spread out of control; the Liberian government quarantined a slum in Monrovia called West Point. On the night of August 21, 2014, a dispute erupted over the quarantines instituted. AFL soldiers in response to controlling the chaos discharged live rounds, injuring three young men of which one later died. The incident provoked a massive public outcry from Liberian human rights activists and the local community. In mid-September, 2014, the Liberian's government board of inquiry issued a report instructing Brig. Gen. Ziankahn to pursue court martial for those responsible for the shooting.

Critics say the AFL's progress is impressive as the America's SSR effort was far from being perfect. Inconsistent funding coupled with lack of coordination and transparency complicated the development of an effective AFL. More importantly, U.S. provided few opportunities for 'local ownership' of the process. The AFL's performance in the mist of the Ebola epidemic proved the critics right. But the security sector is beginning to see how successful SSR means for developing countries that are vulnerable to such crises(Union, 2015).

The Ebola outbreak in West Africa has highlighted plain gaps in Guinea's national healthcare infrastructure. It has also casted spotlights on long-running tensions between the state and the society in the remote areas of the southeast region where the epidemic originated from December 2013. Communities in the southeastern "forest" region are geographically proximate and closely linked to Liberia and Sierra Leone. Those were the worst affected communities. Although, this was the region the virus originated from, many other regions in Guinea have had confirmed Ebola cases since the start of the outbreak, including the densely populated capital, Conakry.

Guinea's bloated and undisciplined military is the underlying cause of instability in the country. Some challenges in reference to the military include an overweening size (Guinea's armed forces, estimated at over 45,000 personnel as at 2010 and is among the region's largest); history of several 
coup attempts, riots, and several serious human rights abuses; and the incomplete integration of past waves of irregular recruits(Bogoch et al., 2015; Forrester et al., 2014). The president leveraged a combination of appointments, promotions, and forced retirements all aimed at controlling the oversized armed forces, especially after the president's house came under armed attack in July 2011. This led to the arrest or dismissal of several prominent military officers. Their ultimate aim and whether they were plotting a coup or not could not be ascertained. The president pledged to prioritise security sector reform (SSR) in the countries interventions, for which the United States provided support for.

The military coup in 2008 appeared to have contributed to the deterioration of discipline and created intra-military divisions along ethnic groups, generational, and factional lines. While credit is given to former president General Sekouba Konaté (who headed the government for most of 2010) and President Condé for improving military discipline, the potential for abuses still remains high. According to the U.S. State Department, "U.S. policy seeks to encourage Guinea's democratic reforms, its positive contribution to regional stability, and sustainable economic and social development". The 2013 legislative election was hailed by the Obama Administration as "a positive advance in Guinea's democratic development"(Goeijenbier et al., 2014; Lewnard et al., 2014). The Administration also called for the fortification of the National Assembly, constructing a transparent judiciary, and preparing adequately for the 2015 Presidential elections.

In reviewing the pre-disaster period, several were made. Since the 1990s, conflict in the Mano River Union has taken an overt sub-regional dimension as armed conflict has spread across borders engulfing both Liberia and Sierra Leone in civil wars. Even though Guinea has been able to maintain its internal peace, the country remains vulnerable.

The conflict within the MRU involves multitude of actors and different factors and these have made it very complex to deal with. Problems within the Mano river union are not easy to fix constraining donors. The sub-region is faced with many crises and limited resources to fix them.They are forced to focus on immediate needs such as restoration of peace, demobilization and reintegration of ex-combatants, and healing the worst form of the pyscho-social and economic trauma of war.

A conflict risk assessment done in the MRU in 2002 showed Guinea and Liberia to be in a medium risk for conflict while Sierra Leone remains in a high risk for conflicts. Although the formation used for the assessment was dated backwards (1995-2000), Liberia has subsequently erupted into open conflict after the assessment and the areas of vulnerability identified by the assessment still appear to be valid.

The political tensions, wars and conflicts in the Mano River Union have had lasting negative impact on the socio- economic development of the sub-region. These have resulted into problem of reconstruction. During the conflicts, infrastructural facilities were wantonly destroyed including health care facilities and security stations(Ayithan et al., 2015; Koonin et al., 2015). Again, unemployment has become a major issue in these post-conflict societies. In countries coming out of conflict, many young people do not only lack employment, they are also denied education and economic empowerment. The conflict in the Mano River Union has also resulted into many people becoming refugees or internally displaced persons.

A great number of people; young, old, male, female, civilians and military men alike, have lost their lives to various wars and conflicts fought in the sub-region. For example, in Liberia, it is estimated that over 250, 000 lives were lost in the country's fourteen year civil war between 1990 and 2004. The same is also said about Sierra Leone where it is estimated that about 200,000 people were killed during the nation's civil war between 1991 and 2001. The political stalemate and periodic eruptions of violence in the Mano river union have resulted in a significant cumulative decline in Gross Domestic Product (GDP). Prospective investors in the region have been turned away because of fear of instability, low profit and loss of investments which have translated into low GDP growth rates. $t$ due to looting during wars. This is evident in the persistent failure to raise investment rate.

According to Michelle et al., (2007), the risk Factors that enhance Disease emergence and transmission in Conflict Situations includes population displacement and environmental conditions; breakdown in infection control; disruption of disease control programs and collapse of health systems. It also includes inadequate surveillance and early warning and response systems; impeded access to populations; development of drug resistance; and movement of refugees and aid workers. 


\subsection{Effect of Ebola and Disaster Risk Management in the Mano River Union}

Liberia, Sierra Leone and Guinea were the most hit in the last Ebola outbreak. This was coupled with the fact that the three countries have endured civil unrest and was recovering from the prolong years of war and instability. The outbreak of EVD in the Mano River union caught all local and international healthcare providers and communities unprepared. Health workers unpreparedness and the lapses in the health-care system added to the spread of infection in hospital between the health workers(Leroy et al., 2015; MacAskill \& Mason, 2014). The response to the epidemic was faced with many challenges such as: healthcare operators lacking training on the management of suspected and confirmed cases; response teams finding difficulty in tracing contacts of probable affected individuals in communities; government and policy makers finding it difficult in resources mobilization following the new outbreaks of infection; distrust of local communities in the control and prevention teams.

According to the Hyogo Framework for Action 2005-2015, for nations and communities to build resilience against disasters the Strategic goals of the Hyogo Framework for Action has to be followed. The strategic goals are integrating Disaster Risk Reduction into sustainable development policies and planning, developing and strengthening institutions, mechanisms and capacities to build resilience to hazards and incorporating risk reduction approaches into emergency preparedness, response, and recovery programmes. Nations need to plan and take actions to ensure that the necessary resources are available, in time, to meet the emergency needs, and that the capacity to use the resources will be in place as well.

The World Health Organization (WHO) declared the Ebola outbreak as a Public Health Emergency of International Concern (PHEIC) on August 8, 2014. On the 25th of October, the WHO reported 10,141 cases and 4,922 deaths, making this ongoing outbreak several times larger than all previous Ebola outbreaks combined(WHO, 2014a, 2016). These numbers may be a drastic underestimation of the true case burden, as more cases have not been reported to the health facility. WHO estimated the true prevalence to be two to four times higher than the reported figures in late August, 2014. The Ebola outbreak is seen to be concentrated in the capitals of Guinea, Liberia, and Sierra Leone, although some of the cases occurred in other parts of the West African countries. In addition, the virus took an international trend. Spain and the United States also reported cases.

The 2014 outbreak caused more cases and deaths than any previous EVD epidemic. The first disease started in the Guéckédou district of Guinea in December 2013. In late April 2014, most cases were reported from Guinea (the country that reported the first case of the disease), with a small number in bordering parts of Liberia and Sierra Leone. There was a dip in reported cases in Guinea and that gave hope to the fact that the epidemic might be beginning to subside and could be confined largely to one country. That hope was actually abandoned as the number of confirmed cases in Liberia and Sierra Leone rose sharply in May 2014 (Frieden et al., 2014). The Ebola Virus Disease has caused immense damage to the three Mano River Union countries. As at March 31, 2015, the three affected countries had recorded about 25,213 cumulative cases with total fatality rate of about 42 per cent or about 10, 460 deaths. The number of death among health care workers in the three States amounted to 495 out of 861 cumulative cases. Guinea recorded the highest fatality rate (66 percent) with 2,314 deaths from 3,492 reported cases followed by Liberia with 4,332 deaths out of 9,712 cases (45 percent) and Sierra Leone with cumulative case of 11,974 and 3,799 deaths (32 percent). The Ebola epidemic has caused the most severe socioeconomic crisis for the leaderships, governments, and citizens of the three affected countries(WHO, n.d., 2014b).

The onset of the Ebola virus disease resulted into a number of public and private health facilities been closed down while the available bed capacity needed for the treatment at existing health facilities was overwhelmed and healthcare delivery services paralyzed(WHO, 2015). As a result of these, responses to non- Ebola related diseases were crowded out by the epidemic and sometimes left to traditional healers thereby increasing the total death toll across the sub-region.

Educational institutions in the region were closed during the period of the outbreak and some of these facilities were being used as holding or Ebola treatment centres. Governments continued to underwrite wages and salaries of teachers in order to manage the epidemic. The impact of prolonged school closures in a region with some of the lowest education indicators further exacerbates an already deplorable situation. The epidemic further worsened the educational situation as many school age girls became teenage parents as a result of the extended school closure. The EVD situation affected the availability of teachers due to death, safety of school premises, and increased the level of vulnerability 
of girls and women. The Ebola epidemic has exacerbated already existing problems such as child labour, gender - based violence and exploitation of, and violence against women and children. The elderly in the society, people with disabilities, chronically ill persons and people living with HIV and other groups who were already vulnerable are now facing additional hardships and social exclusion due to this epidemic.

Agriculture is the main source of livelihoods and employment in the sub-region and has a high percentage of women working in the field. The onset of the Ebola virus disease stalled agricultural activities; about 230,000 people were exposed to severe food insecurity in Guinea; 170,000 people in Liberia; and 120,000 people in Sierra Leone as at January 2015. The total production of food crops is estimated to decline by 3 percent in Guinea; negative 2.9 percent in Liberia; and 5 percent for Sierra Leone.

International and continental airlines were suspended in the three Mano River Union. This resulted in increased costs of insurance and travel, and this negatively affected trade, manufacturing, and the general economy of the sub-region. The Ebola outbreak interrupted and stopped the effective implementation of very important public infrastructure projects, such as energy, road works and a range of construction activities. With the lack of infrastructure, Mano River Union will remain seriously unattractive to investment, coupled with high energy and transport costs thus reducing competitiveness for business transactions in the region. International Health Responses

The health systems in the three Mano River Union Countries were already weak before the Ebola outbreak due to the conflict and war they had experienced, and the Ebola crises overwhelmed them. According to WHO, six components of a health system exist: human resources; governance and leadership; financing; commodities and supply chain networkers; service delivery; and information.

The affected countries faced severe deficiencies in each of these areas before even the outbreak and the outbreak further exacerbated these challenges. In September, the United Nations (U.N.) established the U.N. Mission for Ebola Emergency Response (UNMEER). The UNMEER was to coordinate the international response to the Ebola outbreak. The United Nations Security Council held a special meeting on Ebola. In this meeting, member states were urged to accelerate support for affected countries and to also contribute to the UNMEER plan. The $\$ 988$ million plan outlined was towards addressing the health and social impacts of the Ebola outbreak. Donors were also providing other resources for addressing the Ebola outbreak outside of the UN response plan. The United Nations Office for the Coordination of Humanitarian Affairs (UNOCHA) also estimated that some \$894 million has already been committed to addressing the outbreak and an extra $\$ 938$ million pledged for immediate and long-term preparedness needs(U.S department of health and human services, 2014; USAID, 2014)

The amount of money required for containing the outbreak is rising as the outbreak of the virus keeps spreading. WHO estimated that it would take $\$ 4.8$ million to contain the outbreak but at the end of April, 200 more Ebola cases were discovered in Guinea, less than a dozen in Liberia, and none in Sierra Leone. WHO revised its Ebola response plan by estimating that a rough amount of $\$ 490$ million would be needed to contain the outbreak. At this stage, the outbreak had reached Sierra Leone and Nigeria and had caused 3,685 EVD cases, including 1,841 deaths.

\subsection{Actions Needed}

The Mano river union sub-region must make it mandatory for all countries within the sub-region to have the disaster management division under the ministry of interior and as part of their priority strategies emergency preparedness plans instituted into their interventions with corresponding budgets for disasters(The White House, 2014). Countries already having this division must revisit and enhance the role of disaster management systems in place at both national and sub regional levels. Various countries in the Mano river union should formulate security related programmes and health systemsrelated programmes to repair and correct errors revealed by the Ebola epidemics especially in reference to security sector reform processes.

More Investments should be made in rebuilding resilient health systems. There should be an effective strengthen of the core health system governance and its functions, providing equitable health and nutrition care services. Adequate investment should also be made in integrated community based early warning and disease surveillance systems with response capability. The post-Ebola healthcare 
system, while building on what is left in the country should also rely on the district and community levels interventions, thereby building trust between healthcare providers and the population.

The strengthening of the epidemiological surveillance sub-systems and response capacity at all levels that is national, community and district are very important. This will enable an early detection of disease occurrence and appropriate intervention put in place to mitigate it. Also strengthening governance and accountability of the sector at all levels including adequate funding by the government, capacity building in terms of health management, communication, social mobilization and community participation will help manage and control the escalation of the incidence of diseases.

There should be effective involvement and strengthening of the capacity of all actors (that is the civil society organizations ( $\mathrm{CSO} / \mathrm{s})$, traditional and religious leaders, the media, women and youth, micro, small and medium enterprises (MSMEs) and workers in all sectors to participate in the prevention and management of conflicts and natural disasters as well as health, early warning and rapid response(BBC, 2014b).

There should be a decentralized governance system and delivery of basic services to foster resilience in all the countries. All stakeholders in the various countries should be identified and empowered such that districts and communities acquire a winning formula for gains made so far in the Ebola response. All recovery efforts must build on this momentum in other to operationalize the Government's decentralization programme, including especially the security and justice sectors, which features community participation and community-based accountability mechanisms that are capable of delivering harmonized and equitable basic services and social protection(Chowell \& Nishiura, 2014; Drazen et al., 2014). There nations should also be capable of supporting this policy by allocating national resources to all communities in an equitable manner and to supervise and also coordinate capacity building. This will help ensure that the national social protection system is capable of facing future outbreaks in a well-articulated and transparent way through local delivery channels.

There is the need to improve the management and delivery capacity of the health system in all countries especially post-conflict societies to address the pre-existing vulnerabilities and the impact of the Ebola outbreak. There is the urgent need to develop a preparedness and response plan to respond to a potential post-Ebola food and nutrition crisis, including nutrition-sensitive interventions in the agriculture, social protection and education sectors.

It is of great importance to set up gender-responsive disaster prevention, risk reduction and management schemes, thereby integrating gender equality and women's participation into all strategies and interventions. There is the need to build capacity of women's groups/associations and traditional leaders throughout the outbreak management and recovery process to strengthen the response mechanisms(Leroy et al., 2015; Wamala, Lukwago, Malimbo, \& Nguku, 2012). Government partners have to scale up their support to strengthen institutional capacity so as to ensure gender mainstreaming and gender-responsive recovery.

A higher priority should be accorded the Mano River Union programmes (that is the already planned and approved programmes), especially in field of economic collaboration, natural resource management, joint infrastructure development, early warning systems, disaster risk management and security sector reforms. The lessons learned for effective practice in all these areas during the outbreak and the emergency response phase need to tease out, capitalised upon and carried forward to shape recovery practice and manage future crisis. Finally, all countries must put in place monitoring and evaluation system of the countries strategies and conduct research around the Ebola virus disease.

\section{Conclusion}

It is widely acknowledged that Ebola Virus Disease and its subsequent crisis could not have been anticipated but the scale of the outbreak and the high number of deaths could have been reduced if early warning and resilience systems had been put in place. Again, we can concluded that if greater investments had been made in rebuilding institutional capacity across national systems, especially in the fundamentally fragile environments, a lot could have been done to control and contain the virus. 


\section{Acknowledgment}

I have fully given acknowledgement this study is the result of my own work and investigation as a Master of Art Degree in Gender, Peace and Security student of the Kofi Annan International Peace Training Centre under the supervision of Dr Benjamin Agordzo.

\section{References}

Albrecht, \& Jackson. (2014). Timeline of Security-Sector Reform in Sierra Leone, 1997-2013. 2014, 82(1). http://doi.org/10.1080/02681307.2014.988024

Alexander, Sanderson, Marathe, Lewis, Rivers, Shaman, \& Eubank. (2015a). What Factors Might Have Led to the Emergence of Ebola in West Africa? 9(6). http://doi.org/10.1371/journal.pntd.0003652

Alexis. (2014). Guinea: In Brief. Congressional Research Service. 7(570). Retrieved from www.crs.gov

Arieff, \& McGovern. (2013). "History is stubborn": Talk about Truth, Justice, and National Reconciliation in the Republic of Guinea. Comparative Studies in Society and History. 55(1), 198-225.

Ayithan, Bradfute, Anthony, Stuthman, \& Bavari. (2015). Virus-like particles activate type I interferon pathways to facilitate post-exposure protection against Ebola virus infection. Environ. Res. Public HealthPLoS One, 10(2).

Baize, Pannetier, Oestereich, Rieger, Koivogui, \& Magassouba. (2014). Emergence of zaire ebola virus disease in guinea: preliminary report. $N$ Engl J Med, 371(15), 1418-1425.

BBC, N. (2014a). Recommendations for Breastfeeding/Infant Feeding in the Context of Ebola. Centers for Disease Control and Prevention. Ebola Virus Disease. $B B C$.

BBC, N. (2014b). Seven die in Monrovia Ebola outbreak. BBC.

Bogoch, Creatore, Cetron, Brownstein, \& Pesik. (2015). Assessment of the potential for international dissemination of Ebola virus via commercial air travel during the 2014 west African outbreak. 385(9962), 29-35.

Bryman. (2012). Social Research Methods, 4th Edition (4th edition). Oxford; New York: Oxford University Press.

Camacho, Kucharski, Funk, Breman, \& Edmunds. (2014). Potential for large outbreaks of Ebola virus disease. Epidemics, 9(1), 70-78.

Chan. (2014). Ebola Virus Disease in West Africa - No Early End to the Outbreak. New England Journal of Medicine, 371(13), 1183-1185. http://doi.org/10.1056/NEJMp1409859

Chowell, \& Nishiura. (2014). Transmission dynamics and control of Ebola virus disease (EVD): a review. $B M C M e d, 12(1), 196$.

Drazen, Kanapathipillai, Campion, Rubin, Hamme, \& Morrissey. (2014). Ebola and quarantine. 371(21), 2029-2030.

Forrester, Pillai, Beer, Neatherlin, Massaquoi, \& Nyenswah. (2014). Assessment of ebola virus disease, health care infrastructure, and preparedness - four counties, Southeastern Liberia. MMWR Morb Mortal Wkly Rep, 63(40), 891-893.

Frieden, Damon, Kenyon, \& Nichol. (2014). Ebola 2014 - New Challenges, New Global Response and Responsibility. New England Journal of Medicine, 371(13), 1177-1180. http://doi.org/10.1056/NEJMp1409903 
Gire, Goba, Andersen, Sealfon, Park, Kanneh, \& Sabeti. (2014). Genomic surveillance elucidates Ebola virus origin and transmission during the 2014 outbreak. Science (New York, N.Y.), 345(6202), 1369-1372. http://doi.org/10.1126/science.1259657

Goeijenbier, Kampe, V., Reusken, \& Koopmans. (2014). Ebola virus disease: a review on epidemiology, symptoms, treatment and pathogenesis. Neth J Med, 72(9), 442-448.

Katz, \& Tobian. (2014). Ebola virus disease, transmission risk to laboratory personnel, and pretransfusion testing. 54(12), 3247-3251.

Kodjo. (2015). African Union, ECOWAS, European Union and United Nations Joint Security Sector Assessment Mission to Guinea-Bissau-African Union - Peace and Security Department. http://www.peaceau.org/en/article/african-union-ecowas-european-union-and-united-nationsjoint-security-sector-assessment-mission-to-guinea-bissau

Koonin, Jamieson, Jernigan, Beneden, V., Kosmos, \& Harvey. (2015). Systems for rapidly detecting and treating persons with ebola virus disease - United States. MMWR Morb Mortal Wkly Rep, 64(8), 222-225.

Leroy, Kumulungui, Pourrut, Rouquet, Hassanin, Yaba, \& Swanepoel. (2015). Fruit bats as reservoirs of Ebola virus. 438(7068), 575-576. http://doi.org/10.1038/438575a

Lewnard, Mbah, N., Alfaro-Murillo, Altice, \& Bawo. (2014). Dynamics and control of Ebola virus transmission in Montserrado, Liberia: a mathematical modelling analysis. Lancet Infect Dis, 14(12), 1189-1195.

Lisgis, Welfare, Liberia, Program, \& International, L. (2014). Liberia Demographic and Health Survey 2013. http://www.dhsprogram.com/publications/publication-fr291-dhs-finalreports.cfm

MacAskill, \& Mason. (2014). British troops to be sent to help fight Ebola. http://www.theguardian.com/world/2014/oct/08/british-troops-sent-fight-ebola-sierra-leone

Mano River Union Advocacy. (2015). Mano River Union Advocacy Document | Ebola Recovery Strategies New York 2015.

River, U. M. (2015). Mano River Union Post-Ebola Socio-economic Recovery Programme.

Secretary, O. of the P. (2016). FACT SHEET: U.S. Response to the Ebola Epidemic in West Africa.

SSL, \& International, C. (2014). Sierra Leone Demographic and Health Survey, DHS, 2013 | MamaYe.

Team, W. E. R. (2014). Ebola Virus Disease in West Africa - The First 9 Months of the Epidemic and Forward Projections. New England Journal of Medicine, 371(16), 1481-1495. http://doi.org/10.1056/NEJMoa1411100

The White House. (2014). Embedded Footer.

Theo. (2015). Preventive Medicine: Ebola and Security Sector Reform in Liberia.

Tiaji. (2014). International Health Responses to the Ebola Outbreak in West Africa. Congressional Research Service, 7(570). Retrieved from www.crs.gov

Tracking, F. (2016). Financial Tracking Service (FTS) » Tracking Global Humanitarian Aid Flows.

U.S department of health and human services. (2014). U.S. Public Health Service Commissioned Corps to help treat Ebola patients in Liberia | HHS.gov. http://www.hhs.gov/about/news/2014/09/16/us-public-health-service-commissioned-corps-

help-treat-ebola-patients-in-liberia.html 


\section{UNDP. (2015). Recovering from the Ebola Crisis - Full Report.} http://www.undp.org/content/undp/en/home/librarypage/crisis-prevention-andrecovery/recovering-from-the-ebola-crisis---full-report.html

Union, M. R. (2015). Mano River Union Post-Ebola Socio-economic Recovery Programme.

UNISDR. (2016). United Nations International Strategy for Disaster Reduction. http://www.unisdr.org/

United Nations development group. (2015). Socio-Economic Impact of the Ebola Virus Disease in West Africa. http://www.africa.undp.org/content/rba/en/home/library/reports/socio-economicimpact-of-the-ebola-virus-disease-in-west-africa.html

USAID. (2014). West Africa - Ebola Outbreak - Fact Sheet \#4 (FY 15). https://www.usaid.gov/ebola/fy15/fs04

Wamala, Lukwago, Malimbo, \& Nguku. (2012). Ebola hemorrhagic fever associated with novel virus strain. Emerg Infect Dis., 16(7), 1087-1092.

WHO. (n.d.). WHO | Cuban medical team heading for Sierra Leone. In 2014. http://www.who.int/features/2014/cuban-ebola-team/en/

WHO. (2014a). Ebola Response Roadmap. Switzerland.

WHO. (2014b). Ebola Response Roadmap Situation Report.

WHO. (2015). WHO | Why the Ebola outbreak has been underestimated. http://www.who.int/mediacentre/news/ebola/22-august-2014/en/

WHO. (2016). WHO | Health systems. http://www.who.int/topics/health_systems/en 